\title{
The effects of conditioned taste aversions on the acquisition and maintenance of schedule-induced polydipsia
}

\author{
ANTHONY L. RILEY \\ The American University, Washington, D.C. 20016 \\ ELIZABETH C. LOTTER \\ University of Washington, Seattle, Washington 98195 \\ and \\ PAUL J. KULKOSKY \\ Laboratory of Metabolism, National Institute on Alcohol Abuse and Alcoholism \\ Rockville, Maryland 20852
}

\begin{abstract}
Conditioned taste aversions produced a moderate, but transient, suppression of scheduleinduced polydipsia. This suppression was greater and longer lasting when rats were offered a choice between water and the previously poisoned solution on the polydipsia baseline. A final experiment demonstrated that taste aversions were more effective in suppressing scheduleinduced consumption when superimposed on a developing schedule-induced drinking baseline as opposed to a stable pattern of schedule-induced drinking. It was suggested that scheduleinduced polydipsia is insensitive to conditioned taste aversions. This conclusion was discussed in terms of schedule-induced alcohol consumption and its potential as an animal model of alcoholism.
\end{abstract}

Falk (1961) demonstrated that if water is made continuously available to a rat leverpressing for food on an interval schedule, the rat drinks large quantities of water during the experimental session. Typically, this schedule-induced drinking occurs immediately following the delivery of a food pellet and greatly exceeds the daily home cage consumption of the animal under similar conditions of food deprivation (see Freed, Zec, \& Mendelson, 1978, for a review of schedule-induced polydipsia).

Although water is usually made available to the rat during such conditions, the intake of a wide range of solutions has been assessed, e.g., acetone, alcohol, dextrose, quinine, saccharin, saline, and sucrose (Falk, 1964; Falk \& Samson, 1976; Githens, Hawkins, \& Schrot, 1973; Samson \& Falk, 1974). While schedule-induced consumption of solutions such as alcohol, hypertonic saline, and quinine is reduced in relation to schedule-induced water intake, rats still consume much greater quantities of these solutions under schedule-induction than under ad-lib conditions in the home cage.

In relation to schedule-induced alcohol con-

- The authors would like to thank V. M. LoLordo and R. M. Gilbert for helpful criticisms on an earlier version of this manuscript. Requests for reprints should be sent to Anthony L. Riley, Department of Psychology, The American University, Washington, D.C., 20016. sumption, it has been suggested that the rat's avoidance of voluntary consumption of intoxicating and physical-dependence-producing amounts of alcohol in the home cage may reflect an acquired aversion to the taste as a result of postingestional, pharmacologically aversive properties (Berman \& Cannon, 1974; Deutsch \& Eisner, 1977; Deutsch \& Walton, 1977; Deutsch, Davis, \& Cap, 1976; Deutsch, Walton \& Thiel, 1978). For example, aversions to a novel saccharin solution can be readily established if consumption is followed by injection or intubation of low doses of alcohol (Davison \& House, 1975; Eckardt, 1975; Lester, Nachman, \& LeMagnen, 1970). That rats continue to display schedule-induced alcohol polydipsia suggests that conditioned aversions in general may be ineffective in totally eliminating schedule-induced drinking (Christian, Schaeffer, \& King, 1977; Freed et al., 1978).

Such a conclusion is surprising in light of the general efficacy of conditioned aversion techniques to suppress both deprivation-induced (Garcia \& Ervin, 1968; Riley \& Clarke, 1977) and stimulation-bound consumption (Kulkosky, Riley, Woods, \& Krinsky, 1975; Wise \& Albin, 1973). Aversion training has been effective in suppressing such species-specific behaviors as copulation in hamsters (Johnston, Zahorik, Immler, \& Zakon, 1978) and predation 
in a wide range of carnivorous predators (Garcia, Rusiniak, \& Brett, 1977; Gustavson, 1977).

Early work by Roll, Schaeffer, and Smith (1969) demonstrated that animals $x$-irradiated immediately following polydipsia training in which a saccharin solution replaced water slowly acquired an aversion to saccharin, i.e., schedule-induced drinking was suppressed. This effect, however, was weak and required numerous saccharin-radiation pairings, a finding unlike typical taste aversion training under conditions of water deprivation in which aversions are acquired in a single trial and extremely resistant to extinction (Garcia, Green, \& McGowan, 1969; Riley, Jacobs, \& LoLordo, 1976).

It appears, therefore, that schedule-induced polydipsia is far less affected by the aversive taste properties (Segal \& Deadwyler, 1965) or the pharmacologically aversive consequences (Leander \& McMillan, 1976; Roll et al., 1969; Samson \& Falk, 1974) of the specific solution available during polydipsia training than water-deprivation-induced drinking. Several possibilities, however, limit this general conclusion. First, while alcohol may produce pharmacologically aversive, postingestional consequences that should condition an aversion (Lester et al., 1970), dependence on the drug could be counteracting the aversion. What appears as insensitivity in the schedule-induced polydipsia design could reflect the interaction of these two properties of alcohol. Such an interaction has been suggested for the variability and weakness of morphine-induced taste aversions (Riley, Jacobs, \& LoLordo, 1978). Secondly, in the report by Roll et al. (1969), following a single pairing of saccharin and radiation, subjects were given repeated exposures of the saccharin solution alone in a test of the conditioned aversion. After these test exposures, subjects were given repeated conditioning trials in an attempt to suppress the schedule-induced saccharin polydipsia. It is possible that the difficulty of taste aversion conditioning to affect schedule-induced polydipsia was a result of CS familiarity, a property that reduces conditionability in most classical conditioning paradigms (Elkins, 1973a; Mackintosh, 1974) and not a function of an insensitivity of schedule-induced consumption.

The present series of studies attempted to condition aversions to a novel saccharin solution and assess the effects of this treatment on the acquisition and maintenance of schedule-induced polydipsia. The results allow a conclusion regarding the sensitivity of schedule-induced drinking to aversive taste conditioning.

\section{EXPERIMENT 1}

\section{Method}

Subjects

The subjects were 22 experimentally naive, female rats of Long-
Evans descent, approximately $90-120$ days of age at the beginning of the experiment. The subjects were maintained on a 12 -h light/ 12-h dark cycle for the duration of the experiment.

\section{Apparatus}

The subjects were housed in individual wire-mesh cages. In the front of each cage were two openings into which graduated Nalgene tubes were placed for presentations of water and/or saccharin $(1 \mathrm{~g} / \mathrm{liter})$ during conditioned aversion training. Three Scientific Prototype experimental chambers were used during polydipsia training. A $5 \times 5 \mathrm{~cm}$ brass hopper was located on the front wall $2 \mathrm{~cm}$ above the grid floor and $4 \mathrm{~cm}$ from the left side wall. A graduated drinking tube was located on the left side wall. The spout of the tube protruded approximately $2 \mathrm{~cm}$ into the chamber, $4 \mathrm{~cm}$ above the grid floor and $8 \mathrm{~cm}$ from the front wall.

\section{Procedure}

Phase I: Taste aversion training. On Day 1, all subjects were deprived of water and given ad-lib access to food. On the next day, the subjects were given $20 \mathrm{~min}$ access to water in the home cage. This procedure was repeated daily for 12 consecutive days, at which point all subjects were approaching and drinking from the tube within $2 \mathrm{sec}$ of its presentation. Differential treatment was then administered to two groups of randomly selected subjects. Group $P(n=12)$ was presented with saccharin for $20 \mathrm{~min}$, followed $30 \mathrm{~min}$ later by an intraperitoneal (IP) injection of cyclophosphamide (Cytoxan, Mead Johnson), $50 \mathrm{mg} / \mathrm{kg}$. Group S $(\mathrm{n}=10)$ was given $20 \mathrm{~min}$ access to saccharin, followed $30 \mathrm{~min}$ later by an IP injection of isotonic saline $(.9 \%)$.

Phase II: Polydipsia training. On the day following this food aversion training, all subjects were deprived of food and given ad-lib access to water. Following reduction to $80 \%$ body weight, each subject was removed from its home cage and placed in the experimental chamber for a daily $1-\mathrm{h}$ polydipsia session. During this session, food was presented to each subject independently of its behavior on a variable time (VT) $60-\mathrm{sec}$ schedule. Water was continuously available throughout the session. The total amount of food pellets eaten and water consumed over the session was recorded. This procedure was continued for 11 consecutive days. On Day 12 , the previously poisoned saccharin solution was presented in place of water during the daily freefood presentations. On the following day, water was again made available during the 1 -h session. This procedure of alternating saccharin or water presentations was continued for 4 more days.

\section{Results}

All determinations of statistical significance were made at the level of $\mathrm{p}<.05$, two-tailed.

\section{Phase I: Taste Aversion Training}

Over the 12 water adaptation days, rats in both groups increased consumption of water, drinking approximately $13 \mathrm{ml} /$ day over the final 3 days of water adaptation. There were no significant differences in water consumption between groups at this point. When saccharin replaced water on Day 13, there were no significant changes in consumption from water baseline for either group, both groups drinking approximately $12 \mathrm{ml}$ of saccharin. The groups did not differ on this initial exposure to the novel saccharin solution.

\section{Phase II: Polydipsia training}

There were no significant differences between Group P and Group S in the acquisition of scheduleinduced polydipsia. On Day 1 of polydipsia training, 
both groups drank approximately $10 \mathrm{ml}$ of water. Drinking gradually developed over repeated sessions, reaching a level of approximately $27 \mathrm{ml}$ for each group on the last day of polydipsia acquisition (Day 11).

When saccharin replaced water on the polydipsia baseline (Day 12), a large significant difference emerged between the two groups, with Group P drinking significantly less saccharin than Group $\mathrm{S}$ $[t(20)=7.84]$. The nonpoisoned subjects (Group $S$ ) drank significantly more saccharin during this session than the previous day's baseline $[\mathrm{t}(9)=2.82]$. On the other hand, subjects previously poisoned following saccharin consumption (Group P) drank significantly less saccharin during this session than the previous day's water baseline $[t(11)=6.19]$. When water was reinstated on the next day, both groups returned to their respective water baselines (see Figure 1, Days 12 and 13).

On the second exposure to saccharin, Group S again significantly increased consumption of saccharin above the previous day's water baseline $[\mathrm{t}(9)=3.12]$. Group $\mathrm{P}$, however, did not significantly decrease consumption of saccharin on this test below the previous day's water baseline. Although Group P did not significantly decrease consumption on this exposure, this group still consumed significantly less saccharin than Group S [ $\mathrm{t}(20)=3.16]$, which was increasing consumption of saccharin over sessions.

On the final exposure to saccharin, both Group P and Group S slightly increased consumption of saccharin above the previous day's water baseline, although neither increase was significant. Both groups drank approximately $40 \mathrm{ml}$ during this session. When water was reinstated, both groups returned to their respective water baselines. There were no differences in water consumed on this final session.

\section{Discussion}

It is clear from the data that presentation of a

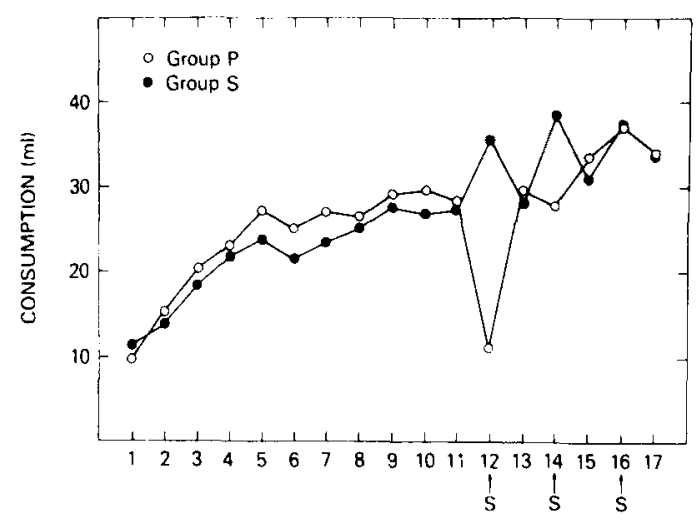

DAYS

Figure 1. Consumption (m) during polydipsia acquisition and subsequent alternating saccharin (S) or water presentations. previously poisoned solution on a stable baseline of schedule-induced drinking results in a substantial but relatively short-duration suppression of consumption. The initial suppression of schedule-induced drinking is similar in degree to suppression of waterdeprivation-induced or stimulation-bound drinking (Garcia \& Ervin, 1968; Kulkosky et al., 1975; Wise \& Albin, 1973). However, the rapid recovery of drinking the previously poisoned solution is quite unlike the prolonged suppression typically seen in the extinction of conditioned taste aversions (Ader, 1973; Braveman, 1974; Garcia et al., 1969). The results in the present report are similar to the rapid extinction of taste aversions seen under extreme deprivation conditions (Grote \& Brown, 1973).

Although the rapid recovery of drinking may be a function of the strong tendency to drink induced by the food pellet delivery, a tendency that can be mimicked to some extent by extreme deprivation, there are a number of possibilities that could account for the rapid recovery of consumption. For example, approximately 12 days intervened between aversion conditioning and the test of the aversion on the polydipsia baseline. While such training-test intervals have exceeded months in typical taste aversion designs with no weakening of the aversion (see Rzoska, 1953), it is possible that a 12-day delay could have attenuated the suppression.

A second and more likely possibility is a confound reported by Peck and Ader (1974). Peck and Ader demonstrated that if taste aversion conditioning was attempted under a specific deprivation state, e.g., water-deprived or non-water-deprived, subsequent aversions were stronger if tested under the deprivation state in which conditioning had occurred, i.e., state dependency for taste aversion conditioning. In the present report, rats acquired a taste aversion while water deprived, but were tested for the aversion on a polydipsia baseline while food deprived. While there may be considerable overlap in these deprivation conditions (Bolles, 1967), the potential for state dependency could account for the rapid recovery in drinking.

Before concluding that schedule-induced drinking is somewhat insensitive (as indexed by recovery) to manipulations that typically suppress deprivationinduced drinking (Freed et al., 1978), it is necessary to examine the interaction of food aversions and polydipsia without the aforementioned confounds. Experiment 2 assessed the effects of poisoning rats following schedule-induced saccharin consumption, i.e., on-baseline conditioning.

\section{EXPERIMENT 2}

\section{Method}

Subjects and Apparatus

The subjects, 22 experimentally naive rats of the same sex, 
strain, and age as those used in the previous experiment, were maintained under the conditions described previously. The housing cages and experimental chambers were the same as those described in Experiment 1.

\section{Procedure}

On Day 1, all subjects were deprived of food and given ad-lib access to water. Following reduction to $80 \%$ of body weight, each subject was removed from its home cage and placed in the experimental chamber for a daily 1-h polydipsia session. During this session, food was presented to each subject independently of its behavior on a VT 60 -sec schedule. Water was continuously available throughout the session. This procedure was continued for 13 consecutive days. On Day 14, a novel saccharin solution was presented in place of water during the daily free-food presentations. Differential treatment was then administered to two groups of randomly selected subjects. Group $P(n=11)$ was given an IP injection of cyclophosphamide, $50 \mathrm{mg} / \mathrm{kg}, 30 \mathrm{~min}$ following $20 \mathrm{~min}$ access to saccharin. Group $\mathrm{S}(\mathrm{n}=11)$ was given an IP injection of isotonic saline $(.9 \%) 30 \mathrm{~min}$ following saccharin access. On the following day, water was again made available during the 1-h session. This procedure of alternating saccharin or water presentations was continued for 6 more days. The injection of cyclophosphamide (Group P) or saline (Group S), however, only followed the first exposure to saccharin on Day 14.

\section{Results}

On Day 1, both groups drank less than $10 \mathrm{ml}$ of water. Drinking gradually developed over repeated sessions, reaching a point of approximately 27 and $22 \mathrm{ml}$ for Groups $P$ and $S$, respectively. The two groups differed significantly in the amount of water consumed on the final 3 days of polydipsia baseline $[t(20)=3.01]$.

When saccharin replaced water on the polydipsia baseline (Day 14), both groups showed a small but nonsignificant increase above their respective previous day's water baseline. There were no significant differences in the amount of saccharin consumed between groups on this exposure to saccharin. When water was reinstated on the next day, Groups $S$ and $P$ returned to their respective water baselines.

On the second exposure to saccharin, i.e., the first exposure following on-baseline conditioning, a significant difference emerged between the two groups of subjects $[\mathrm{t}(20)=5.57]$, with Group $P$ drinking significantly less saccharin than Group S. The nonpoisoned subjects (Group S) drank significantly more saccharin during this session than the previous day's water baseline $[t(10)=2.24]$. On the other hand, subjects poisoned following the initial exposure to saccharin (Group P) drank significantly less saccharin during this session than the previous day's water baseline $[t(10)=4.04]$. When water was reinstated on the next day, both groups returned to their respective prepoison levels of water consumption. There were no significant differences in the amount of water consumed on this water access session (see Figure 2, Days 16 and 17).

On the third exposure to saccharin, Group S again significantly increased consumption of saccharin

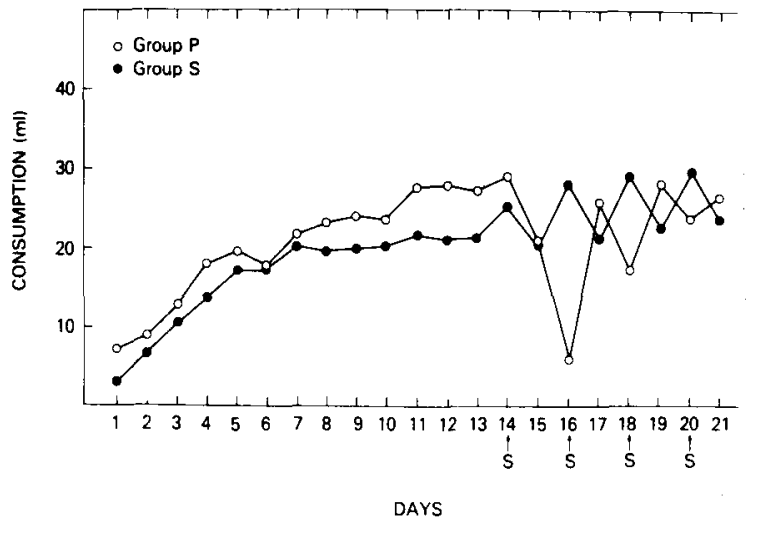

Figure 2. Consumption (ml) during polydipsia acquisition and subsequent alternating saccharin (S) or water presentations.

above the previous day's water baseline $[t(10)=$ 3.53]. Group $P$, however, significantly decreased consumption of saccharin below the previous day's water baseline $[\mathrm{t}(10)=2.71]$. Although Group P drank significantly more saccharin on this session than on the session following conditioning (Day 16), there was a significant difference in the amount of saccharin consumed between Group $P$ and Group $S$ $[\mathrm{t}(20)=3.49]$. When water was reinstated on the next day, both groups returned to their respective water baselines.

On the final exposure to saccharin, Group S again significantly increased consumption of saccharin above the previous day's water baseline $[\mathrm{t}(10)=$ 2.80]. Group $P$, on the other hand, showed a slight but nonsignificant, decrease in saccharin consumption below the previous day's water baseline. There was no significant difference in the amount of saccharin consumed between Group P and Group S on this final access to saccharin, with Groups $P$ and $S$ drinking approximately 29 and $24 \mathrm{ml}$, respectively. When water was reinstated on the next day, both groups returned to their respective water baselines, with the groups not differing significantly in the amount of water consumed.

\section{Discussion}

Similar to Experiment 1, when a solution associated with poison is offered in place of water on a scheduleinduced drinking baseline, there is a marked, but short-duration, suppression of drinking. The recovery of drinking during this on-baseline procedure, however, was less rapid than that in Experiment 1, in which taste aversion conditioning occurred off the polydipsia baseline. It is possible that, because the test for the aversion was immediate and the deprivation states under which the aversion was acquired and tested were similar, the suppression of scheduleinduced drinking was more extended than that seen in Experiment 1 (Peck \& Ader, 1974; Rzoska, 1953). 
Although recovery of drinking in the present study was slightly less rapid than in Experiment 1, recovery was nonetheless extremely faster than typical onebottle extinction of food aversions under water deprivation (Ader, 1973; Braveman, 1974; Garcia et al., 1969). It seems that schedule-induced drinking is only transiently affected by the presentation of a solution either previously or currently paired with illness, suggesting an insensitivity of schedule-induced consumption to aversion-associated taste (Freed et al., 1978; Leander \& McMillan, 1976).

In typical taste aversion conditioning, while rats may consume some of a solution previously paired with illness, if these subjects are given a subsequent choice between the previously poisoned solution and water, they completely avoid consumption of the aversive taste (Elkins, 1973b; Grote \& Brown, 1971). In addition, extinction of aversions proceeds much slower on a two-bottle test than on a one-bottle test (Chambers \& Sengstake, 1976; Elkins 1973b, 1974). In Experiment 3, subjects were poisoned following schedule-induced saccharin consumption. Subjects then were given access to both the poisonassociated saccharin solution and water during the free-food presentations. If schedule-induced drinking is a function of some general tendency to drink, then subjects given a choice between water and the solution associated with poison should avoid consumption of the aversive solution while maintaining schedule-induced consumption of water. The suppression of schedule-induced saccharin consumption on this two-bottle access should recover at a much slower rate than the suppression previously demonstrated in Experiments 1 and 2.

\section{EXPERIMENT 3}

\begin{abstract}
Method
Subjects and Apparatus

The subjects, 10 experimentally naive rats of the same sex, strain, and age as those used in the previous experiments, were maintained under the conditions described previously. The housing cages and experimental chambers were the same as those described in Experiment 1, with one modification. A second graduated drinking tube was added to the left wall of each of the experimental chambers. The spout of this second tube protruded approximately $2 \mathrm{~cm}$ into the chamber and $4 \mathrm{~cm}$ above the grid floor. The spout was located $16 \mathrm{~cm}$ from the front wall approximately $8 \mathrm{~cm}$ to the left of the original tube.
\end{abstract}

\section{Procedure}

On Day 1, all subjects were deprived of food and given ad-lib access to water. Following reduction to $80 \%$ body weight, each subject was removed from its home cage and placed in the experimental chamber for a daily $1-\mathrm{h}$ polydipsia session. During this session, food was presented to each subject independently of its behavior on a VT $60-\mathrm{sec}$ schedule. Water was continuously available throughout the session. However, only one tube was accessible during this phase, with the position of the tube alternating daily between the front $(8 \mathrm{~cm}$ from the front wall) and the back $(16 \mathrm{~cm}$ from the front wall) tube locations. This pro- cedure was continued for 14 consecutive days. On Day 15, a novel saccharin solution was presented in place of water during the daily free-food presentations. The tube location, i.e., front or back, was randomized among subjects. Differential treatment was then administered to two groups of randomly selected subjects. Group $P(n=5)$ was given an IP injection of cyclophosphamide, $50 \mathrm{mg} / \mathrm{kg}, 30 \mathrm{~min}$ following this access to saccharin. Group $S(n=5)$ was given an IP injection of isotonic saline $(.9 \%)$ following saccharin access. On the following day, water was again made available during the 1 -h session. On the next day, all subjects were given access to both saccharin and water during the polydipsia session. The locations of the respective solutions, i.e., front or back, were randomized among subjects. Access to water was given during free-food sessions on the following day. This procedure of alternating saccharin/water or water presentations was continued for 4 more days. The injection of cyclophosphamide (Group P) or saline (Group S), however, only followed the first exposure to saccharin on Day 15.

\section{Results}

On Day 1 of polydipsia training, both groups drank less than $10 \mathrm{ml}$ of water. Drinking gradually developed over repeated sessions, reaching a point of approximately 27 and $24 \mathrm{ml}$ for Groups P and S, respectively. While Group $P$ drank significantly more water than Group S on Days 6-11, there was no significant difference in water consumption over the last 3 days of polydipsia baseline.

When saccharin replaced water on the polydipsia baseline, there was no significant change in consumption from the previous day's water baseline for either group. There was no significant difference in the amount of saccharin consumed between Groups $\mathrm{P}$ and $\mathrm{S}$ on this first exposure to the novel saccharin solution. When water was reinstated on the following day, both groups returned to their respective water baselines, each drinking approximately $25 \mathrm{ml}$.

On the second exposure to saccharin, i.e., the first exposure following on-baseline conditioning, a significant difference emerged between the two groups of subjects, with Group P drinking significantly less saccharin than Group S $[\mathrm{t}(8)=3.50]$. The nonpoisoned subjects (Group S) showed no significant change in consumption from the previous day's water baseline. On the other hand, subjects poisoned following the initial exposure to saccharin (Group P) significantly decreased consumption of saccharin on this session below the previous day's water baseline $[t(4)=3.63]$. When water was reinstated on the following day, both groups returned to their respective water baselines (see Figure 3, Days 17 and 18).

On the third exposure to saccharin, Group S again showed no change in consumption from the previous day's water baseline. Group P, however, significantly decreased consumption of saccharin below the previous day's water baseline $[\mathrm{t}(4)=4.59]$. There were no significant differences between Groups $\mathrm{S}$ and $\mathrm{P}$ in the amount of saccharin consumed on this saccharin 


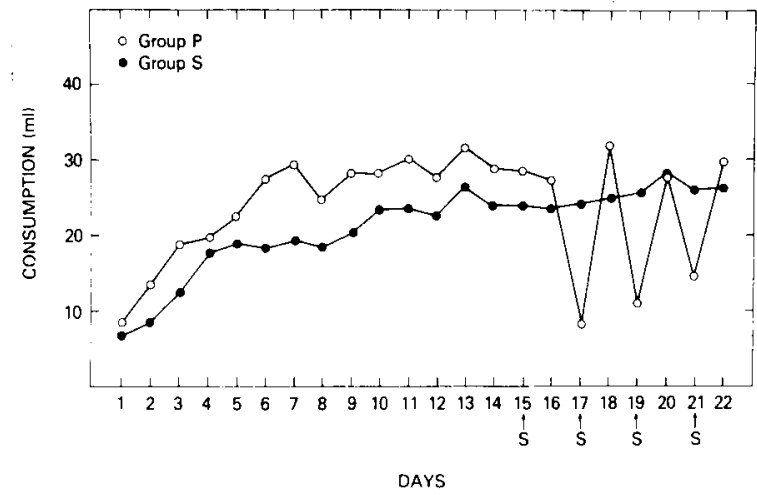

Figure 3. Consumption (ml) during polydipsia acquisition and subsequent alternating saccharin/water or water presentations. Only saccharin consumption is plotted for saccharin/water presentations.

exposure. During this session, Group P showed no significant increase in the amount of saccharin consumed above the level on the second exposure, suggesting little or no recovery of the suppressed drinking. When water was reinstated on the following day, each group returned to its respective water baseline with no significant difference between groups in the amount of water consumed.

On the final exposure to saccharin, neither Group $S$ nor Group P drank significantly different amounts of saccharin from their respective previous day's water baseline. There were no significant differences in amount of saccharin consumed for Groups $S$ and $P$ on this exposure. Group $P$ again showed no significant increase in amount of saccharin consumed above the levels on the first and second exposure. When water was reinstated on the next day, both groups returned to their respective water baselines.

Figure 4 illustrates the aforementioned data according to the location or position of saccharin and water during the two-bottle access on the polydipsia baseline. While subjects in Group P decreased consumption of the saccharin solution on Exposures 2, 3, and 4 (as shown in Figure 3), it is clear from a further analysis that decrements in saccharin consumption from water baseline depended in part upon the particular location of the saccharin solution during the two-bottle exposure. As Figure 4 shows, on the first two-bottle access, Group P markedly decreased consumption of saccharin below baseline when the saccharin solution was in the tube most removed from the pellet hopper. When saccharin was in the position adjacent to the hopper, there was less of a decrease in consumption from the level consumed on the first exposure. In addition to the degree of suppression, recovery of suppression was in part dependent upon saccharin location. While consumption of saccharin in the adjacent,tube recovered to baseline by the fourth exposure, there was no significant change over repeated exposures in the amount of scheduled-induced saccharin consumption from the more removed location.

This effect of the location of saccharin can also be seen in the nonpoisoned subjects (Group S), who drank significantly more saccharin in the adjacent than in the more removed location. The significantly different amounts of saccharin consumed in the more removed location for Groups $\mathrm{P}$ and $\mathrm{S}$ reflects a conditioned taste aversion to saccharin which is only weakly evident in the adjacent location.

\section{Discussion}

When rats were given a choice between water and a saccharin solution paired with poison, scheduleinduced consumption of the previous solution was substantially reduced. Recovery of schedule-induced consumption, however, was again rapid, approximating the levels of control subjects after only two nonpoisoned recovery exposures. While suppression was evident, these results are not consistent with the total suppression of consumption and extreme resistance to extinction typically reported when twobottle aversion tests are given under water-deprivation (Elkins, 1973b, 1974).

Results similar to typical two-bottle tests were seen, however, when position biases were assessed. It is clear from the analysis of fluid position that neartotal suppression and slow recovery of drinking occurred when the previously poisoned saccharin solution was in the back or most removed location. When saccharin was in the tube most adjacent to the pellet, weaker and less prolonged suppression occurred, an effect similar to that seen when only the poison-associated taste was present (see Experiment 2).

Since free-food presentations increase the rat's tendency to drink, it would be expected that taste aversions would have only a moderate and transient effect on schedule-induced drinking. Such an attenuation of aversion effects, however, is not unique to the polydipsia/aversion interaction, since a number of manipulations that increase the rat's tendency to drink, e.g., extreme deprivation (Grote \& Brown,
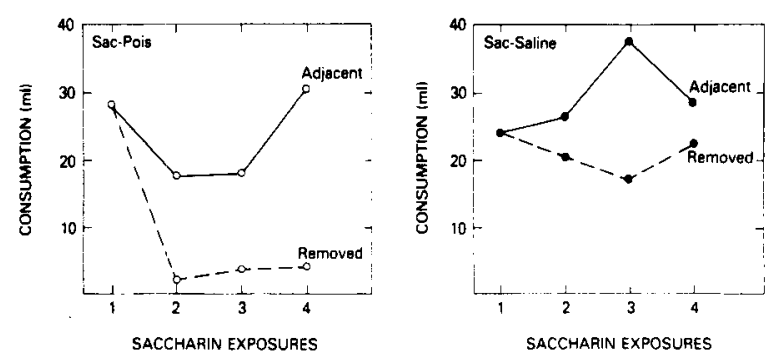

Figure 4. Consumption (ml) during saccharin exposures on polydipsia baseline at adjacent and removed bottle locations for Group P (left) and Group S (right). 
1973), drug-induced dipsogenia (Riley \& Lovely, in press), and lesion or chemical-induced specific hungers (Frumkin, 1975; Gold \& Proulx, 1972) attenuate taste aversions. In this comparison, schedule-induced drinking is no less sensitive than other designs that increase fluid consumption. That prolonged marked suppression in the two-bottle test was position dependent, however, suggests that polydipsia is more insensitive to control by poisonassociated tastes than dipsogenic stimulation.

While the presentation of poison-associated taste on stable polydipsia baselines results in a transient suppression of drinking (Experiments 1 and 2), it is possible that such presentations prior to the establishment of stable schedule-induced consumption might produce a marked and extended suppression. Since schedule-induced consumption develops over repeated sessions, it would be expected that conditioned taste aversions would more effectively suppress schedule-induced drinking during the initial sessions with recovery from this suppression as the tendency to drink increases. Experiment 4 made this final assessment of the effects of conditioned taste aversions on schedule-induced drinking.

\section{EXPERIMENT 4}

\section{Method}

Subjects and Apparatus

The subjects, 12 experimentally naive rats of the same sex, strain, and age as those used in the previous experiments were maintained under the conditions described previously. The housing cages and experimental chambers were the same as those described in Experiment 1.

\section{Procedure}

Phase I: Taste aversion training. On Day 1, all subjects were deprived of water and given ad-lib access to food. On the next day, the subjects were given 20 min access to water in the home cage. This procedure was repeated daily for 12 consecutive days, at which point all subjects were approaching and drinking from the tube within $2 \mathrm{sec}$ of its presentation. Differential treatment was then administered to three groups of randomly selected subjects. Group P $(n=4)$ was presented with saccharin for $20 \mathrm{~min}$, followed $30 \mathrm{~min}$ later by an IP injection of cyclophosphamide, $150 \mathrm{mg} / \mathrm{kg}$. Group SS $(\mathrm{n}=4)$ and Group SW $(\mathrm{n}=4)$ were given $20 \mathrm{~min}$ access to saccharin, followed $30 \mathrm{~min}$ later by an IP injection of isotonic saline $(.9 \%)$.

Phase II: Polydipsia training. On the day following taste aversion conditoning, all subjects were deprived of food and given ad-lib access to water. Following reduction to $80 \%$ body weight, each subject was removed from its home cage and placed in the experimental chamber for a daily 1-h polydipsia session. During this session, food was presented to each subject independently of its behavior on a VT 60 -sec schedule. Groups P and SS had continuous access to the saccharin solution during each polydipsia session. Group SW had continuous access to water during the free-food presentations. This procedure was maintained for 12 consecutive days.

\section{Results \\ Phase I: Taste Aversion Training}

Over the 12 water-adaptation days, rats in each of the three groups increased consumption of water, drinking approximately $13 \mathrm{ml} /$ day over the final 3 days of water adaptation. There were no significant differences in water consumption among groups at this point. When saccharin replaced water on Day 13, there were no significant changes in consumption from water baselines for any group, with each group drinking approximately $12 \mathrm{ml}$ of saccharin. The groups did not differ on this initial exposure to the novel saccharin solution.

\section{Phase II: Polydipsia Training}

Significant differences emerged among groups on the first day of polydipsia training. Group SW, which received access to water during free-food sessions, drank approximately $10 \mathrm{ml}$ of water on Day 1. Group SS, given access to a familiar, nonpoisoned saccharin solution, drank approximately $26 \mathrm{ml}$ on Day 1, an amount significantly different from that drunk by Group SW $[\mathrm{t}(6)=3.61]$. Group $P$, which received access to a previously poisoned saccharin solution, drank only approximately $0.5 \mathrm{ml}$ on Day 1, an amount significantly less than that drunk by either Group SW or Group SS [t(6) = 4.20 and $t(6)=5.65$, respectively] (see Figure 5, Day 1).

Consumption of water for Group SW gradually developed over repeated sessions, reaching a point of approximately $26 \mathrm{ml}$ on the final day of polydipsia training. Consumption of saccharin for Group SS also gradually developed over repeated sessions, reaching a level of approximately $40 \mathrm{ml}$ on the final day of training. Although Group SS drank significantly more saccharin on Days 1 and 12 than Group SW drank of water, the development or pattern of drinking for each of these groups was similar.

Consumption of saccharin for Group $\mathrm{P}$, which began at $0.5 \mathrm{ml}$ on Day 1 also gradually developed over repeated sessions, reaching a level of approximately $31 \mathrm{ml}$ on Day 12. This final level, however,

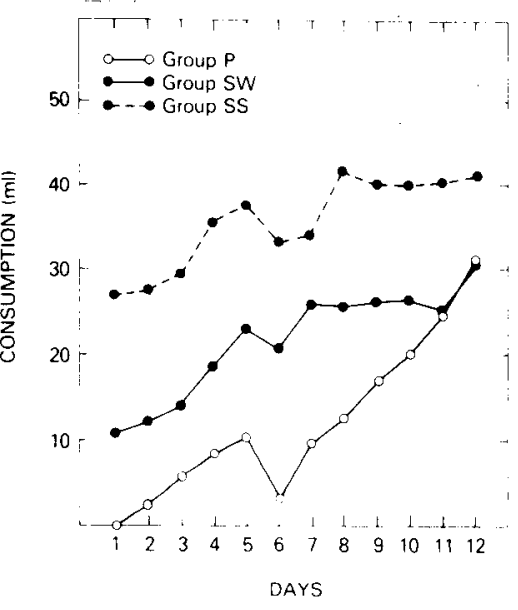

Figure 5. Consumption (ml) during polydipsia acquisition. 
was not significantly different from the Day 1 consumption of saccharin by Group SS, suggesting an extremely attenuated development of scheduleinduced drinking. On the final polydipsia session, Group P drank significantly less saccharin than Group SS, while not drinking significantly different amounts of fluid than Group SW, subjects receiving water throughout training (see Figure 5, Day 12).

\section{Discussion}

When a previously poisoned saccharin solution was given to rats at the beginning of polydipsia training, development of polydipsia was greatly retarded. Only after approximately seven sessions, at which point schedule-induced drinking by control animals had reached asymptote, did consumption of the previously poisoned solution substantially increase. Even after 12 sessions, however, scheduleinduced consumption of the previously poisoned solution was still below consumption of saccharin by the nonpoisoned controls.

This suppression of schedule-induced drinking is in marked contrast to the effect demonstrated once stable polydipsia baselines had been established. Such differential sensitivity to suppression again reflects a general tendency to drink induced by the free-food delivery. When this tendency is weak, e.g., at the beginning of training, suppression is most evident. When this tendency is great, e.g., at asymptotic levels of schedule-induced drinking in the latter stages of training, the suppression is weaker and more transient.

\section{GENERAL DISCUSSION}

As previously suggested by Freed et al. (1978), schedule-induced drinking appears relatively insensitive to conditioned taste aversions. In both Experiments 1 and 2 , while schedule-induced consumption of a previously poisoned solution was substantially reduced, recovery of consumption was complete after only two nonpoisoned presentations. Such rapid recovery of drinking is unlike the prolonged suppression seen when taste aversions are acquired under water deprivation conditions, yet quite similar to the attenuation of aversions demonstrated under conditions of extreme water deprivation (Grote \& Brown, 1973) or following dipsogenic stimulation (Riley \& Lovely, in press).

The insensitivity of schedule-induced polydipsia to taste aversions was also evident in Experiment 3. While the two-bottle choice between water and the poison-associated saccharin solution resulted in stronger and more extended suppression of scheduleinduced drinking, the aversion was not sufficient to counteract a position bias. Schedule-induced consumption of the previously poisoned solution was substantially maintained in the most accessible bottle. Such a position bias seldom is reported to attenuate taste aversions under water deprivation (Carey \& Goodall, 1974; Dragoin, McCleary, \& McCleary, 1971; Elkins, 1973b; Goudie \& Thornton, 1975).

If the insensitivity of schedule-induced polydipsia to taste aversions is a function of an increased tendency to drink following pellet delivery, this insensitivity should be least evident at the beginning of training, a period in which drinking in control animals is only gradually developing. As shown in Experiment 4, suppression of schedule-induced drinking was most pronounced during the first six sessions of polydipsia training. Recovery of scheduleinduced drinking, however, was most rapid during the last 6 days of polydipsia training, a period associated with high asymptotic levels of consumption in control subjects.

The schedule-induced consumption of alcohol becomes somewhat clearer in light of these findings. Repeated consumption of intoxicating and physicaldependence inducing amounts of alcohol is avoided under ad-lib home cage conditions, yet such amounts are rapidly and substantially consumed in a scheduleinduced polydipsia design (Falk \& Sampson, 1976; Hawkins, Schrot, Githen, \& Everett, 1972; Samson $\&$ Falk, 1974). This relative avoidance of alcohol in the home cage has been explained to be a result of an acquired association between the taste of alcohol and the pharmacologically aversive effects of the drug, i.e., a conditioned taste aversion (Berman \& Cannon, 1974; Deutsch \& Eisner, 1977; Deutsch \& Walton, 1977; Deutsch et al., 1976; Deutsch et al., 1978). Although such an aversion may be effective in suppressing water-deprivationinduced drinking (Davison \& House, 1975; Eckardt, 1975; Lester et al., 1970), it may have little or no effect on schedule-induced alcohol consumption, a result consistent with the moderate and transient suppression seen in the present series of experiments in which a novel taste was associated with toxicosis.

The results of the two-bottle choice in Experiment 3 are also consistent with data on schedule-induced alcohol consumption when the rat is given a choice between alcohol and water (Keehn \& Coulson, 1975). On such two-bottle exposures, rats often consume none of the alcohol solution, whereas the same solution is consumed when it is the only solution available. It is also important to note that this suppression of schedule-induced alcohol consumption when alcohol and water are available during polydipsia training is greatly dependent upon the specific location of the alcohol solution (Gilbert, 1976; McMillan, Leander, Ellis, Lucot, \& Frye, 1976). When alcohol is in the most accessible position or closest to the food hopper, schedule-induced alcohol consumption is maintained, a result consistent with 
the position bias noted in Experiment 3. Similar twobottle suppression and position control have been reported with schedule-induced narcotic consumption (Leander \& McMillan, 1976).

It is clear from the data that schedule-induced fluid consumption occurs under conditions that maintain drinking of toxin-associated solutions. These results are consistent with earlier reports of the development and maintenance of scheduleinduced alcohol consumption. Schedule-induced polydipsia of alcohol occurs under conditions in which the pharmacological effects of the alcohol should condition an aversion to the taste of the alcohol and suppress schedule-induced drinking.

Since free-food presentations typically result in high levels of schedule-induced alcohol consumption, a number of researchers have presented scheduleinduced alcohol polydipsia as an animal model of human alcoholism (Falk \& Samson, 1976; Hawkins et al., 1972; Senter \& Sinclair, 1967). Factors such as diet, drugs, strain of animal, stress, and taste have all been manipulated in an attempt to assess their effects on this analog of addiction (Falk \& Samson, 1976; Falk, Samson, \& Tang, 1973; Freed, 1974; Gilbert, 1975; Keehn, 1972; Meisch \& Thompson, 1972; Senter \& Sinclair, 1967). While the procedures and mechanisms underlying schedule-induced alcohol consumption in animals and human alcoholism are clearly varied and different for the two phenomena (Falk et al., 1973; Lester \& Freed, 1972), the fact that consumption is maintained under both conditions despite the possibility of aversive aftereffects of alcohol ingestion offers some support for the continued use of schedule-induced polydipsia in assessing factors affecting human alcohol consumption. Varying the factors that may be regulating or correlated with human alcoholism on a baseline of schedule-induced alcohol consumption may reveal information on the development and maintenance of alcohol ingestion in humans.

\section{REFERENCES}

ADER, R. Effects of early experiences on shock- and illnessinduced passive avoidance behaviors. Developmental Psychobiology, 1973, 6, 547-555.

Berman, R., \& CANNON, D. The effect of prior ethanol experience on ethanol-induced saccharin aversions. Physiology \& Behavior, 1974, 12, 1041-1044.

Bolles, R. Theory of motivation. New York: Harper \& Row, 1967. Braveman, N. Poison-based avoidance learning with flavored or colored water in guinea pigs. Learning and Motivation, 1974, 5, 182-194.

Carey, R., \& Goodall, E. Amphetamine-induced taste aversion: A comparison of d- versus l-amphetamine. Pharmacology, Biochemistry, and Behavior, 1974, 2, 325-330.

Chambers, K., \& Sengstake, C. Sexually dimorphic extinction of a conditioned taste aversion in rats. Animal Learning \& Behavior, 1976, 4, 181-185.
Christian, W., Schaeffer, R., \& King, G. Schedule-induced behavior: Research and theory. Montreal: Eden Press, 1977.

Davison, C., \& House, W. Alcohol as the aversive stimulus in conditioned taste aversion. Bulletin of the Psychonomic Society, $1975,6,49-50$.

Deutsch, J., \& EISNer, A. Ethanol self-administration in the rat induced by forced drinking of ethanol. Behavioral Biology, 1977 , 20, $81-90$.

Deutsch, J., \& Walton, N. A rat alcoholism model in a free choice situation. Behavioral Biology, 1977, 19, 349-360.

Deutsch, J., Davis, J., \& CaP, M. Conditioned taste aversions: Oral and post-ingestional factors. Behavioral Biology, 1976, 18, 545-550.

Deutsch, J., Walton, N., \& Thiel, T. The importance of postingestional factors in limiting alcohol consumption in the rat. Behavional Biology, 1978, 22, 128-131.

Dragoin, W., MCCleary, G., \& MCCleary, P. A comparison of two methods of measuring conditioned taste aversions. Behavior Research Methods \& Instrumentation, 1971, 3, 309-310.

ECKARDT, M. Conditioned taste aversion produced by the oral ingestion of ethanol in the rat. Physiological Psychology, 1975, 3, 317-321.

ELKINs, R. Attenuation of drug-induced bait-shyness to a palatable solution as an increasing function of its availability prior to conditioning. Behavioral Biology, 1973, 9, 221-226. (a)

Elkins, R. Individual differences in bait shyness: Effects of drug dose and measurement technique. The Psychological Record, 1973, 23, 349-358. (b)

Elkins, R. Conditioned flavor aversions to familiar tap water in rats: An adjustment with implications for aversion therapy treatment of alcoholism and obesity. Journal of Abnormal Psychology, 1974, 83, 411-417.

FALK, J. Production of polydipsia in normal rats by an intermittent food schedule. Science, 1961, 133, 195-196.

Falk, J. Studies on schedule-induced polydipsia. In M. Wayner (Ed.), Thirst. New York: Macmillan, 1964.

FALK, J., \& SAmson, H. Schedule-induced physical dependence on ethanol. Pharmacological Reviews, 1976, 27, 449-464.

Falk. J., Samson, H., \& TANG, M. Chronic ingestion techniques for the production of physical dependence of ethanol. In M. Gross (Ed.), Alcohol intoxication and withdrawal: Experimental studies. New York: Plenum Press, 1973.

FreED, E. Fluid selection by rats during schedule-induced polydipsia. Quarterly Journal of the Studies on Alcohol, 1974, 35, 1035-1043.

Freed, W., Zec, R., \& Mendelson, J. Schedule-induced polydipsia: The role of orolingual factors and a new hypothesis. In J. Weijnen \& J. Mendelson (Eds.), Drinking behavior: Oral stimulation, reinforcement and preference. New York: Plenum Press, 1978.

FrumkIN, K. Failure of sodium- and calcium-deficient rats to acquire conditioned taste aversions to the object of their specific hunger. Journal of Comparative and Physiological Psychology, $1975,89,329-339$.

Garcia, J., \& ERvin, F. Gustatory-visceral and telereceptorcutaneous conditioning: Adaptation in internal and external milieus. Communications in Behavioral Biology, 1968, 1, 389-415.

GARCIA, J., GREen, D., \& McGowan, B. X-ray as an olfactory stimulus. In C. Pfaffman (Ed.), Olfaction and taste. New York: Rockfeller University Press, 1969.

Garcia, J., Rusiniak, K., \& Brett, L. Conditioning food-illness aversions in wild animals: Caveat canonici. In H. Davis \& H. Hurwitz (Eds.), Operant-Pavlovian interactions. New Jersey: Erlbaum, 1977.

GilbERT, R. Meal-size effects on schedule-induced ethanol and water consumption. Bulletin of the Psychonomic Society, 1975. 6, 575-577.

GILBERT, R. Shifts in the water and alcohol solution intake by rats under conditions of schedule induction. Journal of Studies on Alcohol, 1976, 37, 940-949. 
Githens, S., Hawkins, T., \& Schrot, J. DRL scheduleinduced alcohol ingestion. Physiological Psychology, 1973, $1,397-400$.

Gold, R., \& Proulx, D. Bait-shyness acquisition is impaired by VMH lesions that produce obesity. Journal of Comparative and Physiological Psychology, 1972, 79, 201-209.

Goudie, A., \& Trorrton, E. Effects of drug experience on drug induced conditioned taste aversions: Studies with amphetamine and fenfluramine. Psychopharmacologia, 1975, 44, 77.82.

Grote, F., \& Brown, R. Conditioned taste aversions: Twostimulus tests are more sensitive than one-stimulus tests. Behavior Research Methods \& Instrumentation, 1971, 3, 311-312.

Grote, F.. \& Brown, R. Deprivation level affects extinction of a conditioned taste aversion. Learning and Motivation, 1973, 4, 314-319.

Gustavson, C. Comparative and field aspects of learned food aversions. In L. Barker, M. Best, \& M. Domjan (Eds.), Leaming mechanisms in food selection. Waco, Texas: Baylor University Press, 1977.

Hawkins, T., Schrot, J., Githens, S., \& Everett, P. Scheduleinduced polydipsia: An analysis of water and alcohol ingestion. In R. Gilbert \& J. Keehn (Eds.), Schedule effects: Drugs, drinking, and aggression. Toronto: University of Toronto Press, 1972.

Johnston, R., Zahorik, D., ImmleR, K., \& ZAKon, H. Alterations of male sexual behavior by learned aversions to hamster vaginal secretion. Journal of Comparative and Physiological Psychology, 1978, 92, 85-93.

KeEHN, J. Effects of trihexyphenidyl on schedule-induced alcohol drinking by rats. Psychonomic Science, 1972, 29, 20-22.

KeEHN, J., \& Coulson, G. E. Schedule-induced choice of water versus alcohol. The Psychological Record, 1975, 25, 325-328.

Kulkosky, P., Riley, A., Woods, S., \& KRINSKY, R. Interaction of brain stimulation and conditioned taste aversion: Osmotically induced drinking. Physiological Psychology, 1975, 3, 297-299.

LEANDER, J., \& MCMillaN, D. Schedule-induced narcotic ingestion. Pharmacological Reviews, 1976, 27, 475-487.

LESTER, D., \& FREED, E. A rat model of alcoholism? Annals of the New York Academy of Sciences, 1972, 197, 54-59.

Lester, D., Nachman, M., \& LeMagnen, J. Aversive conditioning by ethanol in the rat. Quarterly Journal of Studies on Alcohol, 1970, 31, 578-586.
Mackintosh, N. The psychology of animal leaming. New York: Academic Press, 1974.

McMillan, D., Leander, J., Ellis, F., Lucot, J., \& Frye, G. Characteristics of ethanol drinking patterns under scheduleinduced polydipsia. Psycopharmacology, 1976, 49, 49-55.

Meisch, R., \& Thompson, T. Ethanol intake during scheduleinduced polydipsia. Physiology \& Behavior, 1972, 8, 471-475.

PECK, J., \& ADER, R. Illness-induced taste aversion under states of deprivation and satiation. Animal Learning \& Behavior, 1974, 2, 6-8.

Riley, A., \& Clarke, C. Conditioned taste aversions: A bibliography. In L. Barker, M. Best, \& M. Domjan (Eds.), Learning mechanisms in food selection. Waco, Texas: Baylor University Press, 1977.

Riley, A., \& Lovely, R. Chlordiazepoxide-induced reversal of an amphetamine-established aversion: Dipsogenic effects. Physiological Psychology, in press.

Riley, A., JACOBS, W., \& LoLordo, V. Drug exposure and the acquisition and retention of a conditioned taste aversion. Journal of Comparative and Physiological Psychology, 1976, 90, 799-807.

Riley, A., JacoBs, W., \& LoLordo, V. Morphine-induced taste aversions: A consideration of parameters. Physiological Psychology, 1978, 6, 96-100.

Roll, D., Schaeffer, R., \& SMith, J. Effects of a conditioned taste aversion on schedule-induced polydipsia. Psychonomic Science, 1969, 16, 39-41.

RzoskA, J. Bait shyness: A study in rat behavior. British Journai of Animal Behaviour, 1953, 1, 128-135.

Samson, H., \& Falk, J. Schedule-induced ethanol polydipsia: Enhancement by saccharin. Pharmacology, Biochemistry, and Behavior, 1974, 2, 835-838.

SEgal, E., \& Deadwyler, S. Determinants of polydipsia: VI. Taste of the drinking solution on DRL. Psychonomic Science, 1965, 3, 101-102.

SENTER, R., \& Sinclair, J. Self-maintenance of intoxication in the rat: A modified replication. Psychonomic Science, 1967, 9, 291-292.

WISE, R., \& AlBIN, J. Stimulation-induced eating disrupted by a conditioned taste aversion. Behavioral Biology, 1973, 9; 289-297.

(Received for publication May 30, 1978; revision accepted September 5, 1978.) 